author is to be congratulated on producing a book, dealing with the history of pharmacy in Britain, which it is a pleasure to read.

K. Bulloor

\section{PLACE-NAMES OF THE WEST RIDING OF YORKSHIRE}

The Place-Names of the West Riding of Yorkshire

By A. H. Smith. Part 7: Introduction, Bibliography, River-Names, Analyses. (English Place-Name Society, Vol. 36.) Pp. xvii + 307. (Cambridge: At the University Press, 1962.) 35s. net; 6.50 dollars.

$\mathrm{T}$ HE place-names of the West Riding have been examined one by one in six earlier volumes which have already been reviewed in Nature $(191,208 ; 1961$, and $193,918 ; 1962)$. This seventh volume draws the evidence together and presents the general conclusions that emerge from the wealth of detailed evidence. It is a synthesis that is unusual, partly because of its length and partly because of the way in which place-names are related not only to archæological and historical evidence but also to the relief and geology. The distribution of woodland and of marsh and of land over $800 \mathrm{ft}$. above sea-level all take their place in the presentation of the material.

There is a full acount for the first time of the Celtic names of the Riding as a whole in relation to the Celtic kingdom of Elmet, set between the Wharfe and the Aire; this account alone constitutes a notable contribution. We are left with an impression that much of West Yorkshire was but thinly settled and that its occupation by the English did not take place until the seventh centurymaybe more than 150 years after the first coming of the Anglo-Saxons to Britain. Early names are rare or absent; the kingdom of Elmet was not conquered until some time between 616 and 632. English names constitute the majority, but they present few unusual foatures. The Scandinavian settlement of the ninth and tenth centuries was less intensive than elsewhere in Yorkshire. Scandinavian names of Domesday villages amounted to only 13 per cent for the West Riding as compared with 38 per cent for the North Riding and 40 per cent for the East Riding. This 13 per cent was unevenly distributed, and the unevenness is discussed in relation to the geography of the area and to the preceding Anglian settlement. The relative importance of Norse and Danish names is also examined. The evidence as a whole points to "the almost complete and early integration" of the English and the Scandinavians. The fourth group of names-Norman French -is relatively unimportant, but it is full of interest.

One foature of the earlier volumes is the attention devoted to minor names and field names. T'hey continued to be formed as woodland was cleared, as marsh was drained and as moorland was nibbled. The evidence of these lesser names as a whole is conveniently summarized in its geographical, economic and social contexts. The word wulf or ulfr, for example, as found in these lesser names, shows that wolves were being actively eliminated in the twelfth and thirteenth centuries. Through the West Riding, more or less along the Wharfe, ran the linguistic boundary between Northern and Midland dialects. This is not only discussed generally in the Introduction, but also a special section of 18 pages is devoted to detailed points of "Phonology and Dialect".

The synthesis of the evidence as a whole is followed by accounts of river names and road names and by an unusually long and valuable analysis of the elements in West Riding place-names. There is a bibliography and six distribution maps. These all show marsh and land over $800 \mathrm{ft}$., so that the distribution of various types of names can be seen against the geographical background. There is even a geological map printed on tracing paper to serve as an overlay. There is no index because a comprehensive index covering the names of all three Ridings will appear in an eighth volume.

The task of surveying the place-names of such a large county as the West Riding must have been a formidable one. This seventh volume, with its synthesis and analysis of such an enormous mass of varied material, and with its meticulous scholarship, makes a major contribution to the early history and geography of England. Prof. Smith is to be warmly congratulated on what can only be described as a tour de force.

H. C. Darby

\section{A RUSSIAN APPROACH TO WATER RESOURCES}

\section{Ressources en eaux Souterraines}

Classification ot Methodes d'Evaluation. Par Prof. N. A. Plotnikov, avec la collaboration de Prof. G. V. Bogomolov et Prof. G. N. Kamensky. Traduit par Madame M. Laronde. Pp. 194. (Paris: Gauthier-Villars et Cie, 1962.) $30 \mathrm{NF}$.

\section{T} HIS French translation of the standard Russian text on underground water resource exploitation has been prepared under the auspices of Unesco on the recommendation of its Arid Zone Research Consultative Committee. In this way its ideas and methods are made available to specialists not conversant with Russian. The work itself begins with a consideration of the various categories of underground resources, stressing the differences between permanent reserves and fluctuating resources, the influence of the mode of exploitation on the scale of reserves, and the additional relevance of hydrogeology and the ultimate use of the water. This section concludes with, and is summarized by, a lengthy table classifying reserves, and a detailed scheme for evaluating such reserves. The bulk of the book, however, is concerned with methods of determining the quality and quantity of different types of underground resourcesfrom aquifers of various kinds, ascending and descending springs, etc.

Throughout these chapters the approach is consistently one of instruction, and the mothod largely that of the primer. The purpose would seem to be to present a series of guides to action which ensure that a whole variety of themes are given their due consideration. Such a functional approach, while immensely valuable in a strictly practical sense, does not make for particularly interesting reading, save for the specialist. For the latter, however, the methods of quantitative assessment are presented clearly and systematically. Formulæ follow one another logically, and are applied to bodies of data, tabulated in detail, that are derived from numerous specific Russian examples. While this provides excellent instructional material, the virtually complete reliance on Russian data and Russian references in the bibliography prevents useful comparisons being made with work in other areas and countries. This orientation is also reflected both in the type of instructions given, which often assume a particular administrative background, and in the inclusion of one chapter specifically devoted to the problems associated with permafrost conditions.

The printing of this translation is perfectly adequate, formulæ are clear and legible save for the occasional suffix, while tabulated material is well organized and easy to use. The illustrations do not always reach the same satisfactory level, however, although they are usually intelligible. Certainly for anyone concerned with problems associated with underground water resources Mme. Laronde's translation of Prof. Plotnikov's work should prove of the greatest value and interest.

S. Gregory 